\title{
PLACE OF TRANEXAMIC ACID IN TRAUMATIC BRAIN INJURY: A SYSTEMATIC REVIEW AND META-ANALYSIS OF RANDOMIZED CONTROLLED TRIALS
}

\author{
Mahdi Al-Jeabory ${ }^{1,2}{ }^{\oplus}$, Lukasz Szarpak ${ }^{2,3,4} \oplus$, Zubaid Rafique ${ }^{5} \oplus$, Nilesh R. Vasan ${ }^{6}{ }^{\circ}$, \\ Kecskes Attila ${ }^{7}{ }^{(0}$, Aleksandra Gasecka ${ }^{8,9}{ }^{\infty}$, Wladyslaw Gawel ${ }^{10}{ }^{10}$, Michal Pruc ${ }^{1}{ }^{\infty}$, \\ Marek Malysz ${ }^{1}{ }^{(0}$, Milosz J. Jaguszewski ${ }^{11}{ }^{1}$, Ivan Savytskyi ${ }^{12}$, Natasza Blek $^{3} \oplus^{\circ}$, \\ Krzysztof J. Filipiak ${ }^{3}{ }^{\circ}$, Frank W. Peacock ${ }^{5}$ \\ ${ }^{1}$ Outcomes Research Unit, Polish Society of Disaster Medicine, Warsaw, Poland \\ ${ }^{2}$ Research Unit, Polonia Academy, Czestochowa, Poland \\ ${ }^{3}$ Institute of Outcomes Research, Maria Sklodowska-Curie Medical Academy in Warsaw, Poland \\ ${ }^{4}$ Research Unit, Maria Sklodowska-Curie Bialystok Oncology Center, Bialystok, Poland \\ ${ }^{5}$ Henry JN Taub Department of Emergency Medicine, Baylor College of Medicine, Houston, TX, USA \\ ${ }^{6}$ College of Medicine, The University of Oklahoma, USA \\ ${ }^{7}$ NATO Centre of Excellence for Military Medicine, Budapest, Hungary \\ ${ }^{8}$ 1st Chair and Department of Cardiology, Medical University of Warsaw, Poland \\ ${ }^{9}$ Department of Cardiology, University Medical Center Utrecht, CX Utrecht, The Netherlands \\ ${ }^{10}$ Department of Surgery, The Silesian Hospital in Opava, Czech Republic \\ ${ }^{11}$ First Department of Cardiology, Medical University of Gdansk, Poland \\ ${ }^{12}$ International European University, Kyiv, Ukraine \\ ${ }^{13}$ Department of Emergency Medical Service, Wroclaw Medical University, Wroclaw, Poland
}

\begin{abstract}
INTRODUCTION: Traumatic brain injury (TBI) is a leading cause of death and disability. In many cases of TBI-related intracranial hemorrhage $(\mathrm{ICH})$ is associated with a high risk of coagulopathy and may lead to an increased risk of hemorrhage growth. Therefore, tranexamic acid (TXA), which is known as an antifibrinolytic agent that reduces bleeding by inhibiting the breakdown of blood clots, might limit ICH expansion.
\end{abstract}

MATERIAL AND METHODS: We aimed to quantify the effects of TXA in brain injury and thus performed a literature search using PubMed, Web of Science, Scopus, EMBASE, and Cochrane Center Register of Controlled Trials (CENTRAL) for studies that were published between the respective database inception, and April 10, 2021.

RESULTS: A total of nine studies were identified; these included 5845 patients treated with, and 5380 treated without TXA. The 28 -day or in-hospital mortality was $17.8 \%$ for the TXA group, compared with $19.3 \%$ for the no-TXA group (OR $=0.92 ; 95 \% \mathrm{Cl}: 0.83,1.01 ; p=0.08)$. At 6 -months follow-up, mortality was $18.3 \%$ vs $19.9 \%(\mathrm{OR}=0.91 ; 95 \% \mathrm{Cl}: 0.63-1.31 ; \mathrm{p}=0.60)$, with and without TXA, respectively. A Glasgow Outcome Scale less than 4 points at 28 -days follow-up was reported in 3 studies and was $29.8 \%$ vs $34.8 \%$ (OR $=0.91$; $95 \% \mathrm{Cl}: 0.45,1.82 ; \mathrm{p}=0.78$ ), with and without TXA, respectively. No differences were found in adverse events between TXA and non-TXA groups.

CONCLUSIONS: Our analysis found showed no statistical significance between TXA and non-TXA treatment of TBI patients, however, in the TXA group a trend to decrease 28-day mortality compared to non-TXA 
treatment was observed. More high-quality studies are needed to show the significant benefit of using TXA, especially in moderate and severe TBI patient groups.

KEY WORDS: blood conservation, antifibrinolytic, tranexamic acid, hemostasis, head trauma, meta-analysis

Disaster Emerg Med J 2021; 6(4): 155-163

\section{INTRODUCTION}

Traumatic brain injury (TBI), which is a form of acquired brain pathology, occurs when a sudden force inflicts damage to the brain [1]. According to the Centers for Disease Control and Prevention, around 2.5 million people in the U.S. report to the emergency departments seeking help regarding TBI [2]. The consequence of TBI results in almost 6 million Americans living with lifelong complications following TBI [3]. While the classification of the TBI can be complicated, most systems consider physical abnormality and dysfunctional severity to assess the injury [4]. One of the most popular and widespread systems is the Glasgow Coma Scale (GCS). It stratifies injury on a 3-15 point scale; where 13-15 is considered mild, 9-12 moderate, and below 9 to be severe brain injury [5]. When discussing severity, one may also classify TBI depending on the length of unconsciousness, where mild, moderate, or severe injury results in the loss of consciousness in terms of seconds, minutes, or hours, respectively [6]. While the vast majority of TBI represents a mild concussion [7], in which the symptoms resolve within 1-2 weeks, around $15 \%$ of patients suffer long-term complications [8].

Although accounting for a minority of overall cases, severe TBI is a leading cause of morbidity and mortality worldwide [9]. Severe trauma causes may result in coagulopathy [10], with the consequence of bleeding and cerebral edema. Several procedures have been implemented in order to reduce damage caused by this cascade of events such as hyperventilation, diuretics, and CFS drainage [11]. In order to protect the brain, several drugs are used, e.g., barbiturates, [12] which reduce the brain metabolism; however, U.S. Food and Drug Administration (FDA) has not approved any drug therapy for the treatment of TBI. Tranexamic acid has been proposed as a candidate drug in the management of severe TBI due to its ability to decrease the conversion of plasminogen to plasmin, which reduces fibrinolysis and stabilizes the blood clot [13]. At present, whether it is effective in improving outcomes is unclear.

We thus conducted a systematic review of randomized-controlled trials (RCTs) to evaluate the safety and efficacy of tranexamic acid in acute brain injury, hypothesizing that we would find a clinically meaningful result.

\section{MATERIAL AND METHODS}

This systematic review and meta-analysis were performed under the preferred reporting items for systematic review and meta-analysis (PRISMA) guidelines [14]. This study represents a continuation of prior research on the use of TXA previously undertaken by the authors $[15,16]$.

\section{Search strategy}

Two independent reviewers (M.A-J, L.S.) performed a computerized search of EMBASE, PubMed, Scopus, Web of Science and Cochrane Center Register of Controlled Trials (CENTRAL) from database inception until April 10, 2021. We included only English-language publications. Following the strategy, which combined keywords was used: 'tranexamic' or 'TXA' or 'tranexamic acid' or 'hemorrhage control' and 'injuries*' or 'trauma' or 'wounds' or 'head injury' or 'brain injury' or 'traumatic brain injury' or 'TBI' and 'prehospital' or 'military' or 'combat' or 'civil's or 'emergency medicine' or 'ED' or 'ER'. Additionally, we manually searched references listed in reports and review articles to identify potentially missed trials.

\section{Selection criteria}

Studies that were included in this meta-analysis had to fulfill the following PICOS criteria: 1. Participants, patients with head injury 18 years old or older; 2. Intervention, tranexamic acid treatment; 3. Comparison, non-TXA treatment; 4 . Outcomes, detailed information for survival or mortality; 5 . Study design, randomized controlled trials comparing TXA and non-TXA care for their effects in patients with brain injury. Studies were excluded if they were reviews, observational studies, animal studies, case reports, letters, conference or poster abstracts, or articles not containing original data. 


\section{Data extraction}

Two reviewers (M.A-J, and L.S.) independently extracted all important information from the full-text original publications and entered it into an electronic data sheet specifically designed for this trial. Any disagreements were discussed and resolved in a consensus meeting with the third reviewer (A.G.). Extracted information included: year of study, country, study design, patient demographics, and study outcomes. Data were extracted for the following outcomes: 28-day or in-hospital mortality, Glasgow Outcome Scale (GOS) less than 4 points in 28-days follow-up [17], length of stay in Intensive Care Unit (ICU), and in-hospital and adverse events including thrombotic events. We also extracted data for longer follow-up if available. Duplicate reports from the same study were excluded.

\section{Risk of bias and quality assessment}

Two investigators (M.A-J, and L.S.) independently evaluated studies for risk of bias and quality assessment. Any disagreements were discussed and resolved in a consensus meeting with the third reviewer (A.G.). The RoB 2 tool (revised tool for risk of bias in randomized trials) was used to assess the quality of randomized studies [18] and the ROBINS-I tool (tool to assess the risk of bias in non-randomized studies of interventions) was used to assess the quality of non-randomized trials [19]. The risk of bias assessments was visualized using the Robvis application [20]. The scale has seven main domains (confounding, participant selection, classification of interventions, deviation from interventions, missing data, outcome measurement, and selection of reported results) and assigns one point for each of the following four judgments: critical, serious, moderate, and low. The review authors' judgments about each risk of bias item are provided in Figures 4-5 in Supplementary File 1.

To assess the quality of evidence we applied the Grading of recommendations Assessment, Development, and Evaluation (GRADE) approach [21] with GRADEpro software (version 3.6 for MacOS). Moreover, the quality of evidence was rated (presence or absence) on the following variables: inconsistency, indirectness, imprecision of the results, and publication bias. The quality of evidence for the main outcomes was graded as high, low, and very low.

\section{Outcomes}

The primary outcome of the current meta-analysis was 28-day or in-hospital mortality. The secondary outcomes were Glasgow Outcome Scale (GOS) less than 4 points in 28-days follow-up, length of stay in Intensive Care Unit (ICU) and in hospital, and adverse events including thrombotic events.

\section{Statistical analysis}

We performed statistical analysis using Review Manager (version 5.4., Nordic Cochrane Centre, The Cochrane Collaboration, Copenhagen, Denmark). To calculate the pooled odds ratio (OR) and $95 \%$ confidence interval $(\mathrm{Cl})$ of binary outcomes trial data were combined using the Mantel-Haenszel estimator. For continuous outcomes, the pooled mean difference with $95 \% \mathrm{Cl}$ were calculated using inverse-variance estimator. When the continuous outcomes were reported in a study as median, range, and interquartile range, we estimated means and standard deviations using the formula described by Hozo et al. [22] .

Statistical heterogeneity was assessed by the Cochrane Q statistic and I2 statistic which indicates the percentage of variability due to heterogeneity rather than sampling error [23]. A p-value $<0.10$, and $12>50 \%$, indicated heterogeneity. This helps avoid false-negative results and the inclusion of such results in the meta-analysis. We performed a sensitivity analysis using the Hartung-Knapp-Sidik-Jonkman method when the number of studies was less than 10 [24]. Moreover, the random-effects model was used for analyses [25]. A p-value $<0.05$ was taken to indicate statistical significance [26]. Statistical testing was 2-tailed.

We planned a priori to investigate potential publication bias using a funnel plot if it included over 10 trials for an outcome. For continuous outcomes, the Egger test was used to detect funnel plot asymmetry [27]. For dichotomous outcomes, we used the arcsine test. We considered publication bias to be present when the $p$-value was $<0.1$ in the asymmetry test.

\section{RESULTS}

\section{Study selection and characteristics}

We identified 547 articles using the predefined search strategy. Of these, 96 were excluded because of duplication. After an assessment of the titles and abstracts, 415 publications were excluded as not relevant to the analyses. After examination of the full text of the selected articles, we finally include 9 randomized controlled trials for this meta-anal- 


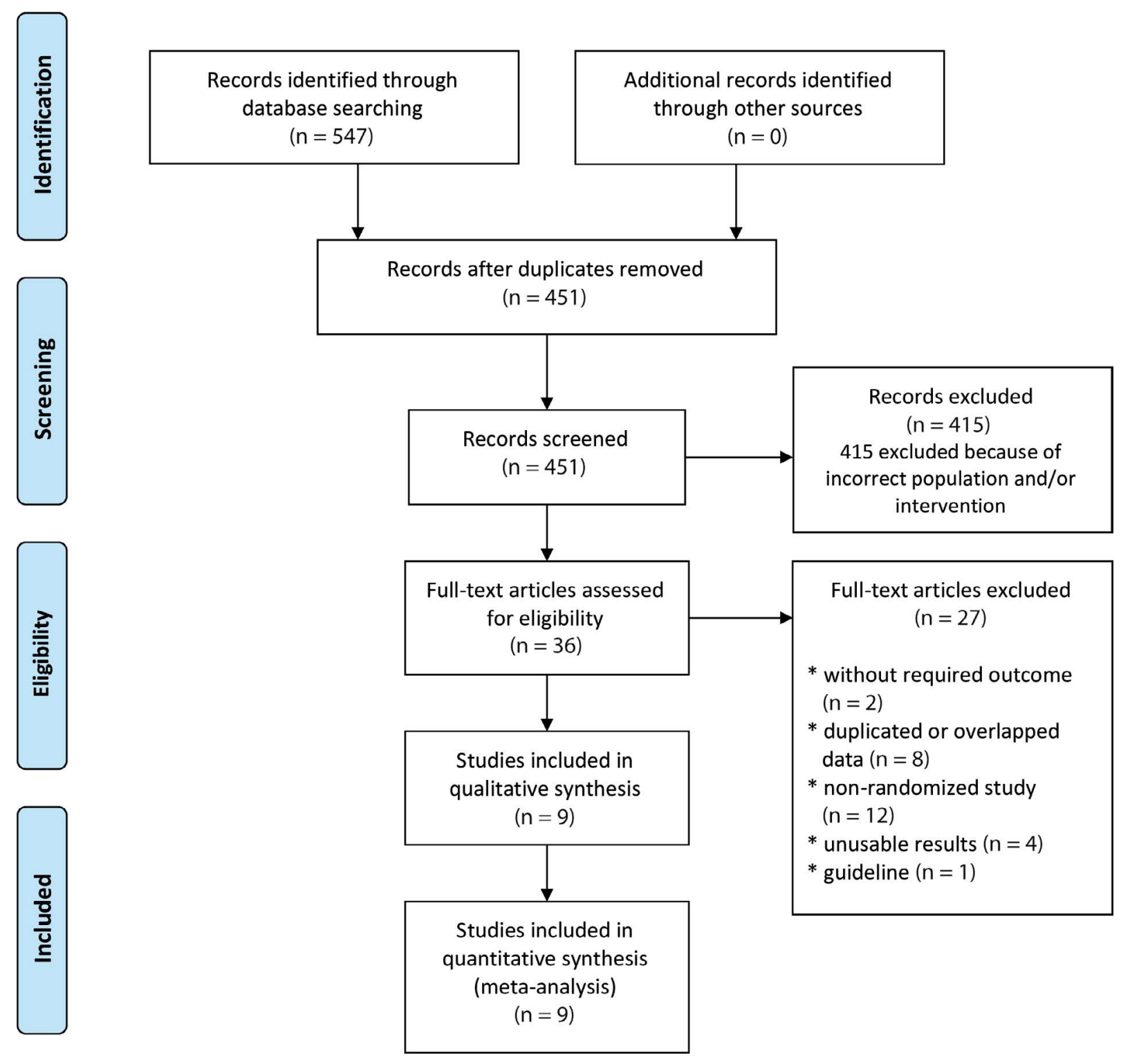

FIGURE 1. Meta-analysis flow chart of included and excluded studies

ysis. We display the process of study selection in the flowchart (Fig. 1). We summarize the details of selected trials in Table 1.

Of the nine trials meeting the inclusion criteria, a total of 5845 patients were treated with, and 5380 without, TXA [17, 28-35]. Four studies were conducted in Iran [31-34], and one in each of the following countries: Tunisia [28] and Thailand [35]. One study was performed in cooperation between the USA and Canada [17], and there were 2 multi-country studies involving more than 2 countries $[29,34]$.

\section{Outcomes}

Twenty-eight-day or in-hospital mortality were reported in six studies [17, 28-35]. It was $17.8 \%$ with and $19.3 \%$ without TXA $(\mathrm{OR}=0.92 ; 95 \% \mathrm{Cl}$ : $0.83-1.01 ; p=0.08 ; 12=0 \%$; Fig 2). Mortality rate between TXA vs non-TXA group was not statistically different at 7 -days $(14.3 \%$ vs $6.8 \%$ respectively; $\mathrm{OR}=2.28 ; 95 \% \mathrm{Cl}: 0.57-9.15 ; \mathrm{p}=0.25)$ and 6 -months (18.3\% vs $19.9 \%$; OR $=0.91 ; 95 \% \mathrm{Cl}$ : $0.63-1.31 ; p=0.60 ;$ SDF).

Glasgow Outcome Scale (GOS) less than 4 points at 28-days follow-up was reported in three studies [28, 34,35$]$ and was $29.8 \%$ with TXA compared to $34.8 \%$ in the non-TXA group $(\mathrm{OR}=0.91 ; 95 \% \mathrm{Cl}: 0.45,1.82 ; \mathrm{p}=0.78$; $12=73 \%$; Fig. 3A). GOS less than 4 points at 6 -months follow-up was reported in two studies and was $35.8 \%$ vs $34.3 \%(\mathrm{OR}=0.76 ; 95 \% \mathrm{Cl}$ : 


\begin{tabular}{|c|c|c|c|c|c|c|c|c|c|c|}
\hline \multirow{2}{*}{ Trial } & \multirow{2}{*}{ Country } & \multirow{2}{*}{ Study design } & \multicolumn{4}{|c|}{ TXA group } & \multicolumn{4}{|c|}{ Non-TXA group } \\
\hline & & & No & Age & Sex/male & ISS & No & Age & Sex/male & ISS \\
\hline $\begin{array}{l}\text { Chakroun-Walha } \\
\text { et al. } 2019\end{array}$ & Tunisia & $\begin{array}{l}\text { Prospective randomized } \\
\text { study }\end{array}$ & 96 & $\begin{array}{c}44 \pm \\
20\end{array}$ & NS & $\begin{array}{c}21.8 \\
\pm \\
23.2 \\
\end{array}$ & 84 & $\begin{array}{c}39 \pm \\
18\end{array}$ & NS & $\begin{array}{c}23.5 \\
\pm \\
25.6 \\
\end{array}$ \\
\hline CRASH-3 2019 & $\begin{array}{l}\text { Multi- } \\
\text { country }\end{array}$ & $\begin{array}{l}\text { Randomized, placebo- } \\
\text { controlled trial }\end{array}$ & 4649 & $\begin{array}{c}41.7 \\
\pm \\
19.0\end{array}$ & $\begin{array}{c}3,742 \\
(80.5 \%)\end{array}$ & NS & 4,553 & $\begin{array}{c}41.9 \\
\pm \\
19.0\end{array}$ & $\begin{array}{c}3,660 \\
(80.4 \%)\end{array}$ & NS \\
\hline $\begin{array}{l}\text { Fakharian et al. } \\
2017\end{array}$ & Iran & $\begin{array}{l}\text { Double-blind, } \\
\text { randomized clinical trial }\end{array}$ & 74 & $\begin{array}{c}42.3 \\
\pm \\
18.3\end{array}$ & $\begin{array}{c}67 \\
(90.5 \%)\end{array}$ & NS & 75 & $\begin{array}{c}39.3 \\
\pm \\
18.1\end{array}$ & $\begin{array}{c}66 \\
(88.0 \%)\end{array}$ & NS \\
\hline Jokar et al. 2017 & Iran & $\begin{array}{l}\text { Single-blinded, } \\
\text { controlled, randomized } \\
\text { trial }\end{array}$ & 40 & $\begin{array}{c}35.4 \\
\pm \\
14.6 \\
\end{array}$ & $\begin{array}{c}32 \\
(40.0 \%)\end{array}$ & NS & 40 & $\begin{array}{c}36.2 \\
\pm \\
14.9 \\
\end{array}$ & $\begin{array}{c}28 \\
(70.0 \%)\end{array}$ & NS \\
\hline $\begin{array}{l}\text { Mojallal et al. } \\
2020\end{array}$ & Iran & $\begin{array}{l}\text { Double-blind controlled } \\
\text { clinical trial }\end{array}$ & 56 & $\begin{array}{l}41.15 \\
\pm \\
20.3 \\
\end{array}$ & $\begin{array}{c}40 \\
(70.1 \%)\end{array}$ & NS & 44 & $\begin{array}{c}37.40 \\
\pm \\
19.6 \\
\end{array}$ & $\begin{array}{c}40 \\
(90.9 \%)\end{array}$ & NS \\
\hline $\begin{array}{l}\text { Mousavinejad et al. } \\
2020\end{array}$ & Iran & $\begin{array}{l}\text { A double-blind, } \\
\text { randomized, and } \\
\text { placebo-controlled trial }\end{array}$ & 20 & $\begin{array}{c}54.89 \\
\pm \\
19.1\end{array}$ & $\begin{array}{c}14 \\
(70.0 \%)\end{array}$ & NS & 20 & $\begin{array}{l}55.16 \\
\pm \\
18.15\end{array}$ & $\begin{array}{c}12 \\
(60.0 \%)\end{array}$ & NS \\
\hline Perel et al. 2012 & $\begin{array}{l}\text { Multi- } \\
\text { country }\end{array}$ & $\begin{array}{l}\text { A prospective } \\
\text { randomised controlled } \\
\text { trial }\end{array}$ & 133 & $\begin{array}{l}36.2 \\
\pm 14\end{array}$ & $\begin{array}{c}111 \\
(83.5 \%)\end{array}$ & NS & 137 & $\begin{array}{l}37 \pm \\
13.7\end{array}$ & $\begin{array}{c}117 \\
(85.4 \%)\end{array}$ & NS \\
\hline $\begin{array}{l}\text { Rowell et al. } \\
2020\end{array}$ & $\begin{array}{l}\text { USA } \\
\text { /Canada }\end{array}$ & $\begin{array}{l}\text { A randomized, } \\
\text { double-blind, 3-group, } \\
\text { multicenter phase II } \\
\text { trial }\end{array}$ & 657 & $\begin{array}{l}40.4 \\
\pm 5.1\end{array}$ & $\begin{array}{c}482 \\
(73.4 \%)\end{array}$ & $\begin{array}{c}17.3 \\
\pm \\
3.2\end{array}$ & 309 & $\begin{array}{l}38 \\
\pm 5\end{array}$ & $\begin{array}{c}233 \\
(75.4 \%)\end{array}$ & $\begin{array}{l}17.5 \\
\pm 3\end{array}$ \\
\hline $\begin{array}{l}\text { Yutthakasemsunt } \\
\text { et al. } 2013\end{array}$ & Thailand & $\begin{array}{l}\text { A double blinded, } \\
\text { placebo controlled } \\
\text { randomized trial }\end{array}$ & 120 & $\begin{array}{c}34.8 \\
\pm \\
16.0\end{array}$ & $\begin{array}{c}103 \\
(85.8 \%)\end{array}$ & $\begin{array}{l}24.7 \\
(5.7)\end{array}$ & 118 & $\begin{array}{c}34.1 \\
\pm \\
15.3\end{array}$ & $\begin{array}{c}107 \\
(90.7 \%)\end{array}$ & $\begin{array}{c}25.4 \\
\pm \\
5.7\end{array}$ \\
\hline
\end{tabular}

\begin{tabular}{|c|c|c|c|c|c|c|c|c|c|c|c|}
\hline Study or Subgroup & \multicolumn{2}{|c|}{ TXA } & \multicolumn{2}{|c|}{ Non-TXA } & Weight & $\begin{array}{c}\text { Odds Ratio } \\
\mathrm{M}-\mathrm{H}, \text { Random, } 95 \% \mathrm{Cl}\end{array}$ & \multicolumn{3}{|c|}{$\begin{array}{c}\text { Odds Ratio } \\
\text { M-H, Random, } 95 \% \mathrm{Cl}\end{array}$} & & \\
\hline Chakroun-Walha 2019 & 27 & 96 & 19 & 84 & $2.1 \%$ & $1.34[0.68,2.64]$ & & & & & \\
\hline CRASH-3 2019 & 855 & 4613 & 892 & 4514 & $88.6 \%$ & $0.92[0.83,1.03]$ & & & & & \\
\hline Fakharian 2017 & 2 & 74 & 3 & 75 & $0.3 \%$ & $0.67[0.11,4.11]$ & & & & & \\
\hline Mousavinejad 2020 & 3 & 20 & 3 & 20 & $0.3 \%$ & $1.00[0.18,5.67]$ & & & & & \\
\hline Rowell 2020 & 94 & 657 & 53 & 309 & $7.1 \%$ & $0.81[0.56,1.16]$ & & & & & \\
\hline Yutthakasemsunt 2013 & 12 & 120 & 17 & 118 & $1.6 \%$ & $0.66[0.30,1.45]$ & & & & & \\
\hline Total $(95 \% \mathrm{Cl})$ & & 5580 & & 5120 & $100.0 \%$ & $0.92[0.83,1.01]$ & & & & & \\
\hline Total events & 993 & & 987 & & & & & & & & \\
\hline $\begin{array}{l}\text { Heterogeneity: } \mathrm{Tau}^{2}=0 \\
\text { Test for overall effect: } Z\end{array}$ & $\begin{array}{l}0 ; \mathrm{Chi}^{2}= \\
1.74(\mathrm{P}\end{array}$ & $\begin{array}{l}=2.48, \\
=0.08\end{array}$ & $d f=5(P$ & $=0.78$ & 8); $1^{2}=0 \%$ & & $0.1 \quad 0.2$ & $0.5_{\text {TXA }}{ }^{1}$ & Non-TXA & 5 & 10 \\
\hline
\end{tabular}

FIGURE 2. Forest plot of 28-day or in-hospital mortality in TXA vs non-TXA group. The center of each square represents the weighted odds ratio for individual trials, and the corresponding horizontal line stands for a $95 \%$ confidence interval. The diamonds represent pooled results

$0.35-1.67 ; p=0.50 ; 12=55 \% ;$ Fig. $3 B$ ) with and without TXA, respectively.

Length of stay in ICU was reported in two studies $[28,30]$ and was $14.7 \pm 15.7$ for TXA, and $11.4 \pm 12.1$ days for the non-TXA group $(\mathrm{MD}=2.85 ; 95 \% \mathrm{Cl}:-0.07,5.76 ; \mathrm{p}=0.06 ; \mathrm{I} 2=0 \%$;
Figure 4A). Two studies reported length of hospital stay for TXA and non-TXA cohorts [28, 30]. The average length of hospital stay was $14.3 \pm 14.9$ days, vs $14.4 \pm 14.0$ days $(\mathrm{MD}=-0.30 ; 95 \% \mathrm{Cl}:-3.39$, 2.79; $\mathrm{p}=0.85 ; \mathrm{I} 2=0 \%$; Fig. $4 \mathrm{~B}$ ), with and without TXA, respectively. 


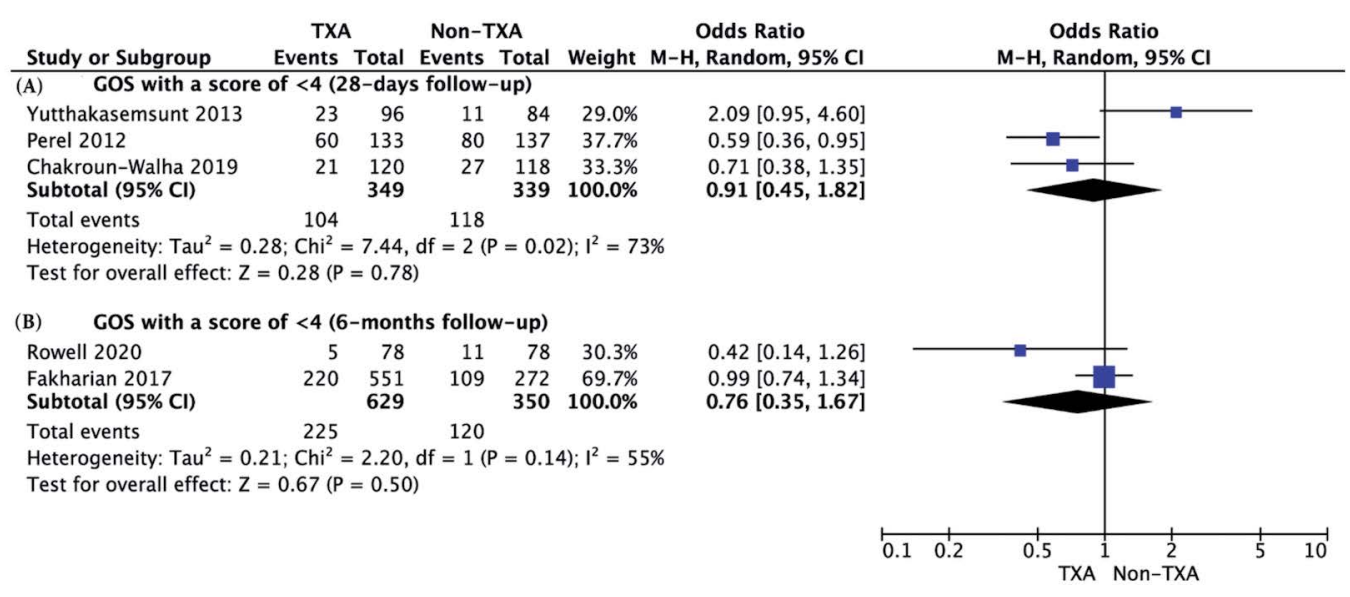

FIGURE 3. Forest plot of Glasgow Outcome Scale less than 4 points at 28-days (A) and 6 months follow-up (B) in TXA vs non-TXA group. The center of each square represents the weighted odds ratio for individual trials, and the corresponding horizontal line stands for a $95 \%$ confidence interval. The diamonds represent pooled results

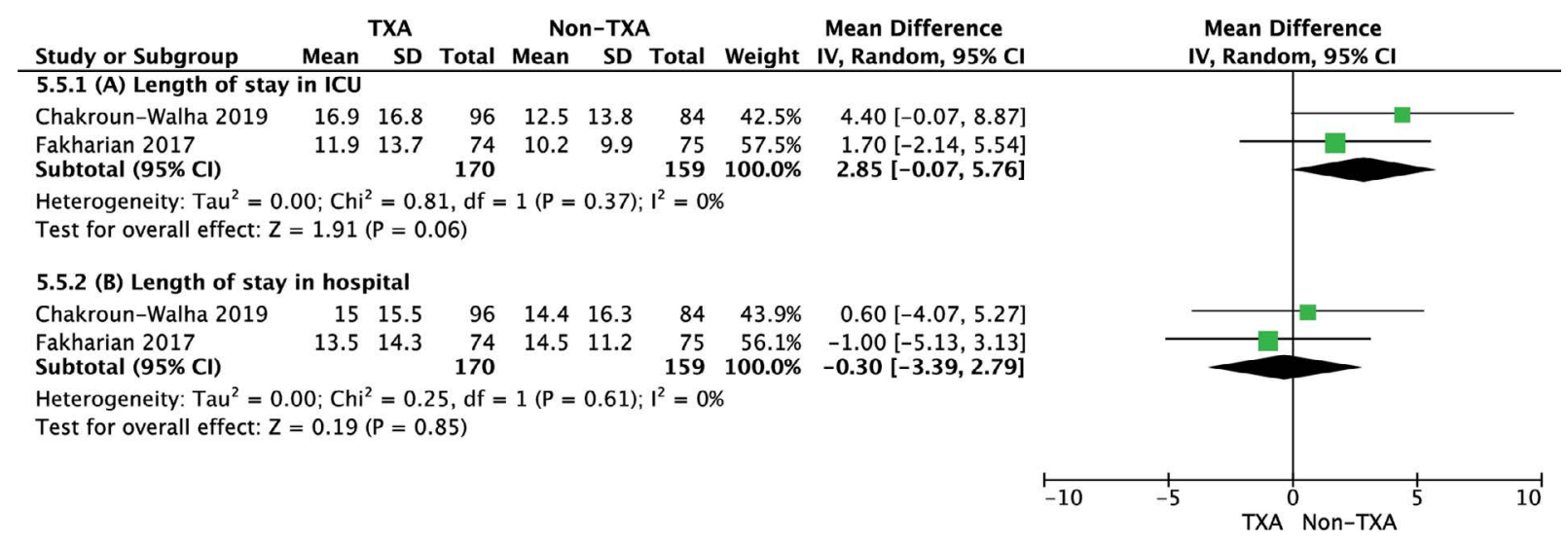

FIGURE 4. Forest plot of length of stay in an intensive care unit (ICU) (A) and length of hospital stay (B) in TXA vs non-TXA group. The center of each square represents the weighted mean difference for individual trials, and the corresponding horizontal line stands for a $95 \%$ confidence interval. The diamonds represent pooled results

In the case of the TXA group, the most frequently observed adverse event (in 28-day or in-hospital follow-up) was a seizure, which occurred in $3.2 \%$ of patients in TXA group compared to $2.9 \%$ in non-TXA group $(\mathrm{OR}=1.12 ; 95 \% \mathrm{Cl}$ : $0.92,1.36$; $p=0.27 ; 12=0 \%)$. In the case of other complications, no differences were observed between TXA and non-TXA groups (Tab. 2).

\section{DISCUSSION}

This meta-analysis was designed to evaluate the safety and efficacy of TXA in the management of TBI. We found no statistically significant differences in both short- and long-term mortality between patients who received TXA and those who did not. However, while those findings are not statistically significant we observed that TXA decreases mortality in a 28-days period compared to non-TXA treatment $(17.5 \%$ vs $19.0 \%$, respectively; $p=0.06)$. Interestingly the authors of the CRASH-3 trial, the largest trial to date on the use of TXA, reported that the early administration (within 3 hours following injury) reduces head injury-related mortality in patients with mild-to-moderate, but not in those with severe head injury [29]. Similarly, Sprigg et al. [36] reported improvement in short-term mortality with TXA, but that long-term status was the same as in the nonTXA administered group.

Others report no mortality effect, although a study by Jokar [31] demonstrated a potential TXA benefit by a reduced size of intracranial hemorrhage. While these findings are supported by Yutthakasemsunt [35] and Mousavinejad, [33] Fakharian [30] 


\begin{tabular}{|c|c|c|c|c|c|c|c|c|}
\hline \multirow[t]{2}{*}{ Adverse event } & \multirow{2}{*}{$\begin{array}{c}\text { No of } \\
\text { studies }\end{array}$} & \multicolumn{2}{|c|}{ Events/participants } & \multicolumn{2}{|c|}{ Events } & \multicolumn{2}{|c|}{$\begin{array}{l}\text { Heterogeneity } \\
\text { between trials }\end{array}$} & \multirow{2}{*}{$\begin{array}{c}p \text {-value for } \\
\text { differences } \\
\text { across groups }\end{array}$} \\
\hline & & TXA group & Non-TXA group & OR & $95 \% \mathrm{Cl}$ & $p$-value & $I^{2}$ statistic & \\
\hline All vascular occlusive event & 2 & $\begin{array}{c}146 / 7016 \\
(2.1 \%)\end{array}$ & $\begin{array}{c}132 / 6589 \\
(2.0 \%)\end{array}$ & 0.90 & $0.70-1.14$ & 0.21 & $37 \%$ & 0.38 \\
\hline Stroke & 3 & $\begin{array}{c}62 / 7136 \\
(0.9 \%)\end{array}$ & $\begin{array}{c}55 / 6707 \\
(0.8 \%)\end{array}$ & 0.95 & $0.66-1.37$ & 0.31 & $15 \%$ & 0.78 \\
\hline Pulmonary embolus & 4 & $\begin{array}{c}44 / 7232 \\
(0.6 \%)\end{array}$ & $\begin{array}{c}39 / 6791 \\
(0.6 \%)\end{array}$ & 1.22 & $0.45-3.27$ & 0.06 & $65 \%$ & 0.70 \\
\hline Deep vein thrombosis & 4 & $\begin{array}{c}35 / 7232 \\
(0.5 \%)\end{array}$ & $\begin{array}{c}28 / 6791 \\
(0.4 \%)\end{array}$ & 0.95 & $0.58-1.57$ & 0.60 & $0 \%$ & 0.84 \\
\hline Gastrointestinal bleeding & 2 & $\begin{array}{c}24 / 6479 \\
(0.4 \%)\end{array}$ & $\begin{array}{c}36 / 6398 \\
(0.6 \%)\end{array}$ & 0.66 & $0.40-1.11$ & 0.66 & $0 \%$ & 0.11 \\
\hline Myocardial infarction & 2 & $\begin{array}{c}23 / 7016 \\
(0.3 \%)\end{array}$ & $\begin{array}{c}21 / 6589 \\
(0.3 \%) \\
\end{array}$ & 0.98 & $0.54-1.79$ & 0.39 & $0 \%$ & 0.95 \\
\hline Renal failure & 1 & $\begin{array}{c}100 / 6359 \\
(1.6 \%)\end{array}$ & $\begin{array}{c}84 / 6280 \\
(1.3 \%)\end{array}$ & 1.18 & $0.88-1.58$ & NA & NA & 0.27 \\
\hline Seizure & 2 & $\begin{array}{c}228 / 7016 \\
(3.2 \%)\end{array}$ & $\begin{array}{c}193 / 6589 \\
(2.9 \%)\end{array}$ & 1.12 & $0.92-1.36$ & 0.49 & $0 \%$ & 0.27 \\
\hline
\end{tabular}

found that administration of TXA did not change the size of intracranial hemorrhage nor provide beneficial effects on clinical outcomes.

The lack of clinical outcome benefit was also reflected in our secondary outcome analysis. We found Glasgow Outcome Scale scored below 4 was not significantly different in those receiving TXA or not. In fact, the number of patients who scored below 4 was higher in the TXA group. The study by Roberts [37] revealed that the timing of the TXA administration is crucial. The early administration (up to 3 hours) reduces mortality regardless of confounding factors, while the administration after the 3-hour mark increases the risk of death due to bleeding.

The length of stay in the ICU and the overall length of stay, although not statistically significant was surprisingly shorter for the non-TXA group. This might indicate that the use of TXA does not improve outcomes measured by the time spent in the ICU nor shortens the overall hospitalization time in TBI patients. This stands in contrast to overall trauma patients who benefit from the administration of TXA [37].

The most frequently observed adverse event following TBI was seizures. Although not significantly different, the TXA group experienced 1.12 increase in seizure occurrence. This finding stands in line with those studies that report increased risk of seizure with TXA administration in a dose-dependent manner [38]. Other complications which were not signif- icant but occurred at a numerically higher rate were thrombotic in nature. TXA administration increased the risk of thrombotic events [39] and should be taken into account when treating with this agent. Although some authors [40] indicate that the neurological outcomes after TXA administration in trauma are better than in the control group, possibly due to reduced cytotoxicity in the TLR4/TNF axis [41], it is worth noting that several studies blatantly forbid the use of TXA due to increased risk of thrombosis without additional clinical benefit $[42,43]$.

The results of our study should be interpreted in the context of its limitations. Most studies were of small size and thus at risk of overestimating treatment effects and underreporting relevant adverse effects. Furthermore, the findings of the CRASH-3 trial due to the high number of patients may distort the results, which is a major limitation in the interpretation of the data.

Substantial heterogeneity was observed and contributed to lowering the evidence grade from high to moderate, however, this value is still high enough to justify the conclusions.

\section{CONCLUSIONS}

In summary, our analysis found showed no statistical significance between TXA and non-TXA treatment of TBI. 


\section{Conflict of interest}

All authors declare no conflict of interest.

\section{REFERENCES}

1. Evaluation of the Disability Determination Process for Traumatic Brain Injury in Veterans. 2019, doi: 10.17226/25317.

2. Maas AIR, Menon DK, Adelson PD, et al. InTBIR Participants and Investigators. Traumatic brain injury: integrated approaches to improve prevention, clinical care, and research. Lancet Neurol. 2017; 16(12): 987-1048, doi: 10.1016/S1474-4422(17)30371-X, indexed in Pubmed: 29122524.

3. de la Tremblaye PB, O'Neil DA, LaPorte MJ, et al. Elucidating opportunities and pitfalls in the treatment of experimental traumatic brain injury to optimize and facilitate clinical translation. Neurosci Biobehav Rev. 2018; 85: 160-175, doi: 10.1016/j.neubiorev.2017.05.022, indexed in Pubmed: 28576511.

4. Saatman KE, Duhaime AC, Bullock R, et al. Workshop Scientific Team and Advisory Panel Members. Classification of traumatic brain injury for targeted therapies. J Neurotrauma. 2008; 25(7): 719-738, doi: 10.1089/neu.2008.0586, indexed in Pubmed: 18627252.

5. Teasdale $G$, Jennett $B$. Assessment of coma and impaired consciousness. A practical scale. Lancet. 1974; 2(7872): 81-84, doi: 10.1016/ s0140-6736(74)91639-0, indexed in Pubmed: 4136544.

6. Thal SC, Neuhaus W. The blood-brain barrier as a target in traumatic brain injury treatment. Arch Med Res. 2014; 45(8): 698-710, doi: 10.1016/j.arcmed.2014.11.006, indexed in Pubmed: 25446615.

7. Report to Congress on Mild Traumatic Brain Injury in the United States: Steps to Prevent a Serious Public Health Problem. PsycEXTRA Dataset. 2003, doi: 10.1037/e371602004-001.

8. Alexander MP. Mild traumatic brain injury: pathophysiology, natural history, and clinical management. Neurology. 1995; 45(7): 1253-1260, doi: 10.1212/wnl.45.7.1253, indexed in Pubmed: 7617178.

9. Johnson WD, Griswold DP. Traumatic brain injury: a global challenge. Lancet Neurol. 2017; 16(12): 949-950, doi: 10.1016/S14744422(17)30362-9, indexed in Pubmed: 29122521.

10. Chang $R$, Cardenas JC, Wade $C E$, et al. Advances in the understanding of trauma-induced coagulopathy. Blood. 2016; 128(8): 1043-1049, doi: 10.1182/blood-2016-01-636423, indexed in Pubmed: 27381903.

11. Narayan RK, Maas AIR, Servadei F, et al. Traumatic Intracerebral Hemorrhage Study Group. Progression of traumatic intracerebral hemorrhage: a prospective observational study. J Neurotrauma. 2008; 25(6): 629-639, doi: 10.1089/neu.2007.0385, indexed in Pubmed: 18491950.

12. Roberts I, Sydenham E. Barbiturates for acute traumatic brain injury. Cochrane Database Syst Rev. 2012; 12: CD000033, doi: 10.1002/14651858.CD000033.pub2, indexed in Pubmed: 23235573.

13. Pabinger I, Fries $D$, Schöchl $H$, et al. Tranexamic acid for treatment and prophylaxis of bleeding and hyperfibrinolysis. Wien Klin Wochenschr. 2017; 129(9-10): 303-316, doi: 10.1007/s00508-017-1194-y, indexed in Pubmed: 28432428.
14. Moher D, Shamseer L, Clarke M, et al. PRISMA-P Group. Preferred reporting items for systematic review and meta-analysis protocols (PRISMA-P) 2015 statement. Syst Rev. 2015; 4: 1, doi: 10.1186/20464053-4-1, indexed in Pubmed: 25554246.

15. Al-Jeabory M, Szarpak L, Attila K, et al. Efficacy and Safety of Tranexamic Acid in Emergency Trauma: A Systematic Review and Meta-Analysis. J Clin Med. 2021; 10(5), doi: 10.3390/jcm10051030, indexed in Pubmed: 33802254.

16. Al-Jeabory M, Gasecka A, Wieczorek W, et al. Efficacy and safety of tranexamic acid in pediatric trauma patients: Evidence from meta-analysis. Am J Emerg Med. 2021 [Epub ahead of print], doi: 10.1016/j. ajem.2021.02.009, indexed in Pubmed: 33722435.

17. Rowell SE, Meier EN, McKnight B, et al. Effect of Out-of-Hospital Tranexamic Acid vs Placebo on 6-Month Functional Neurologic Outcomes in Patients With Moderate or Severe Traumatic Brain Injury. JAMA. 2020; 324(10): 961-974, doi: 10.1001/jama.2020.8958, indexed in Pubmed: 32897344.

18. Sterne JAC, Savović J, Page MJ, et al. RoB 2: a revised tool for assessing risk of bias in randomised trials. BMJ. 2019; 366: 14898, doi: 10.1136/ bmj.14898, indexed in Pubmed: 31462531.

19. Sterne JAC, Hernán MA, Reeves $B C$, et al. ROBINS-l: a tool for assessing risk of bias in non-randomised studies of interventions. BMJ. 2016; 355: i4919, doi: 10.1136/bmj.i4919, indexed in Pubmed: 27733354.

20. McGuinness LA, Higgins JPT. Risk-of-bias VISualization (robvis): An $R$ package and Shiny web app for visualizing risk-of-bias assessments. Res Synth Methods. 2021; 12(1): 55-61, doi: 10.1002/jrsm.1411, indexed in Pubmed: 32336025.

21. Guyatt GH, Oxman AD, Vist GE, et al. GRADE Working Group. GRADE: an emerging consensus on rating quality of evidence and strength of recommendations. BMJ. 2008; 336(7650): 924-926, doi: 10.1136/ bmj.39489.470347.AD, indexed in Pubmed: 18436948.

22. Hozo SP, Djulbegovic B, Hozo I. Estimating the mean and variance from the median, range, and the size of a sample. BMC Med Res Methodol. 2005; 5: 13, doi: 10.1186/1471-2288-5-13, indexed in Pubmed: 15840177.

23. Higgins JPT, Thompson SG, Deeks JJ, et al. Measuring inconsistency in meta-analyses. BMJ. 2003; 327(7414): 557-560, doi: 10.1136/ bmj.327.7414.557, indexed in Pubmed: 12958120.

24. IntHout J, Ioannidis JPA, Borm GF. The Hartung-Knapp-Sidik-Jonkman method for random effects meta-analysis is straightforward and considerably outperforms the standard DerSimonian-Laird method. BMC Med Res Methodol. 2014; 14: 25, doi: 10.1186/1471-2288-14-25, indexed in Pubmed: 24548571.

25. Schober $P$, Vetter TR. Meta-Analysis in Clinical Research. Anesth Analg. 2020; 131(4): 1090-1091, doi: 10.1213/ANE.0000000000005001, indexed in Pubmed: 32925329.

26. Safiejko K, Smereka J, Filipiak KJ, et al. Effectiveness and safety of hypotension fluid resuscitation in traumatic hemorrhagic shock: a systematic review and meta-analysis of randomized controlled trials. Cardiol J. 2020 [Epub ahead of print], doi: 10.5603/CJ.a2020.0096, indexed in Pubmed: 32648249. 
27. Higgins JPT, Altman DG, Gøtzsche PC, et al. Cochrane Bias Methods Group, Cochrane Statistical Methods Group. The Cochrane Collaboration's tool for assessing risk of bias in randomised trials. BMJ. 2011; 343: d5928, doi: 10.1136/bmj.d5928, indexed in Pubmed: 22008217.

28. Chakroun-Walha 0 , Samet $A$, Jerbi $M$, et al. Benefits of the tranexamic acid in head trauma with no extracranial bleeding: a prospective follow-up of 180 patients. Eur J Trauma Emerg Surg. 2019; 45(4): 719-726, doi: 10.1007/s00068-018-0974-z, indexed in Pubmed: 29922895.

29. CRASH-3 trial collaborators. Effects of tranexamic acid on death, disability, vascular occlusive events and other morbidities in patients with acute traumatic brain injury (CRASH-3): a randomised, placebo-controlled trial. Lancet. 2019; 394(10210): 1713-1723, doi: 10.1016/50140-6736(19)32233-0, indexed in Pubmed: 31623894.

30. Fakharian E, Abedzadeh-Kalahroudi M, Atoof F. Effect of Tranexamic Acid on Prevention of Hemorrhagic Mass Growth in Patients with Traumatic Brain Injury. World Neurosurg. 2018; 109: e748-e753, doi: 10.1016/j.wneu.2017.10.075, indexed in Pubmed: 29074420.

31. Jokar A, Ahmadi K, Salehi T, et al. The effect of tranexamic acid in traumatic brain injury: A randomized controlled trial. Chin J Traumatol. 2017; 20(1): 49-51, doi: 10.1016/j.cjtee.2016.02.005, indexed in Pubmed: 28209450.

32. Mojallal F, Nikooieh $M$, Hajimaghsoudi $M$, et al. The effect of intravenous tranexamic acid on preventing the progress of cerebral hemorrhage in patients with brain traumatic injuries compared to placebo: A randomized clinical trial. Med J Islam Repub Iran. 2020; 34: 107, doi: 10.34171/mjiri.34.107, indexed in Pubmed: 33315982.

33. Mousavinejad M, Mozafari J, Ilkhchi RB, et al. Intravenous Tranexamic Acid for Brain Contusion with Intraparenchymal Hemorrhage: Randomized, Double-Blind, Placebo-Controlled Trial. Rev Recent Clin Trials. 2020; 15(1): 70-75, doi: 10.2174/1574887114666191118111826, indexed in Pubmed: 31744452.

34. Perel P, Al-Shahi Salman R, Kawahara T, et al. CRASH-2 (Clinical Randomisation of an Antifibrinolytic in Significant Haemorrhage) intracranial bleeding study: the effect of tranexamic acid in traumatic brain injury--a nested randomised, placebo-controlled trial. Health Technol Assess. 2012; 16(13): iii-xii, 1, doi: 10.3310/hta16130, indexed in Pubmed: 22417901.
35. Yutthakasemsunt $S$, Kittiwatanagul W, Piyavechvirat $P$, et al. Tranexamic acid for patients with traumatic brain injury: a randomized, double-blinded, placebo-controlled trial. BMC Emerg Med. 2013; 13: 20, doi: 10.1186/1471-227X-13-20, indexed in Pubmed: 24267513.

36. Sprigg N, Flaherty K, Appleton JP, et al. Tranexamic acid to improve functional status in adults with spontaneous intracerebral haemorrhage: the TICH-2 RCT. Health Technol Assess. 2019; 23(35): 1-48, doi: 10.3310/hta23350, indexed in Pubmed: 31322116.

37. Roberts I, Edwards P, Prieto D, et al. Tranexamic acid in bleeding trauma patients: an exploration of benefits and harms. Trials. 2017; 18(1): 48, doi: 10.1186/s13063-016-1750-1, indexed in Pubmed: 28143564.

38. Murkin JM, Falter F, Granton J, et al. High-dose tranexamic Acid is associated with nonischemic clinical seizures in cardiac surgical patients. Anesth Analg. 2010; 110(2): 350-353, doi: 10.1213/ ANE.0b013e3181c92b23, indexed in Pubmed: 19996135.

39. Myers SP, Kutcher ME, Rosengart MR, et al. Tranexamic acid administration is associated with an increased risk of posttraumatic venous thromboembolism. J Trauma Acute Care Surg. 2019; 86(1): 20-27, doi: 10.1097/TA.0000000000002061, indexed in Pubmed: 30239375.

40. Cole E, Davenport $R$, Willett $K$, et al. Tranexamic acid use in severely injured civilian patients and the effects on outcomes: a prospective cohort study. Ann Surg. 2015; 261(2): 390-394, doi: 10.1097/ SLA.0000000000000717, indexed in Pubmed: 25412319.

41. Yoshizaki S, Kijima K, Hara M, et al. Tranexamic acid reduces heme cytotoxicity via the TLR4/TNF axis and ameliorates functional recovery after spinal cord injury. J Neuroinflammation. 2019; 16(1): 160, doi: 10.1186/s12974-019-1536-y, indexed in Pubmed: 31358003.

42. Spinella PC, Thomas KA, Turnbull IR, et al. TAMPITI Investigators. The Immunologic Effect of Early Intravenous Two and Four Gram Bolus Dosing of Tranexamic Acid Compared to Placebo in Patients With Severe Traumatic Bleeding (TAMPITI): A Randomized, Double-Blind, Placebo-Controlled, Single-Center Trial. Front Immunol. 2020; 11: 2085, doi: 10.3389/fimmu.2020.02085, indexed in Pubmed: 33013880.

43. Hu W, Xin Y, Chen $X$, et al. Tranexamic Acid in Cerebral Hemorrhage: A Meta-Analysis and Systematic Review. CNS Drugs. 2019; 33(4): 327-336, doi: 10.1007/s40263-019-00608-4, indexed in Pubmed: 30741383 . 